\title{
Sticky care and conference travel: unpacking care as an explanatory factor for gendered academic immobility
}

\author{
Emily F. Henderson ${ }^{1}$ (D) \\ Published online: 6 May 2020 \\ (C) The Author(s) 2020
}

\begin{abstract}
While there is increasing awareness of the contributing effect of the academic mobility imperative on gendered inequalities in the academic profession at large, there is a missing link in current research on this topic. Namely, while 'care' is often named as the explanatory factor for why women, and to an extent professionals of any gender at peak childrearing age, are less mobile, this article argues that care is insufficient as an explanatory factor for immobility. Care and other terms such as 'family responsibilities' and 'domestic obligations' come to serve as a shorthand or explanatory factor for gendered immobility, but these terms elide the complexity of the relationship between care and mobility. This article argues that, without a fuller understanding of how care and mobility intersect, inclusivity drives run the risk of misunderstanding or even reproducing the problem. The specific mobility addressed here is international conference travel as a form of short-term academic mobility which contributes to academic career success and the perpetuation of a mobile academic ideal. The article elaborates a novel conceptual construct, 'sticky care', which is applied to empirical data from a diary-interview study of the impact of caring responsibilities on academics' conference participation. Two dominant mobility-related strategies are elaborated: 'night/s away' and 'get back'. The overarching ambition of this article is at a conceptual level: to bring more complexity and nuance to the concept of care when it is mobilized as an explanatory factor for (gendered) immobility and indeed for inequalities in the academic profession at large.
\end{abstract}

Keywords Conferences · Academic mobility · Academic profession · Gender - Care

Emily F. Henderson

e.henderson@warwick.ac.uk

1 Department of Education Studies, University of Warwick, Coventry, UK 


\section{Introduction}

In an increasingly globalized higher education sector, academics are required to demonstrate evidence of international experience and collaboration as a 'criterion of excellence' for recruitment and promotion (Herschberg et al. 2018). While university rankings and national research bodies are promoting the international mobility agenda (Lim and Williams Øerberg 2017), research on equality and diversity in the academic profession highlights the unequal challenges of engaging in a mobile academic career, particularly for women (Jöns 2011; Leemann 2010). This contemporary issue can be framed as two competing, incompatible imperatives: the mobility imperative and the equality or inclusion imperative (Henderson and Moreau 2020). While there is increasing awareness of the contributing effect of the mobility imperative on gendered inequalities in the academic profession at large (Blackmore 2014; Nielsen 2017), there is a missing link in current research on this topic. Namely, while 'care' is often named as the explanatory factor for why women, and to an extent professionals of any gender at peak childrearing age, are less mobile (Viry et al. 2015), this article argues that care and other terms such as 'family responsibilities' and 'domestic obligations' come to serve as a shorthand or explanatory factor for immobility. However, these terms elide the complexity of the relationship between care and mobility. This article builds on other sociologically oriented research on care and the academic profession (Hook 2016; Moreau and Robertson 2017; Amsler and Motta 2019) to specifically unpack care in relation to academic mobility, arguing that, without the fuller understanding of how care and mobility intersect that this article proposes, inclusivity drives run the risk of misunderstanding or even reproducing the problem.

While this article is envisaged as a contribution to the field of academic mobilities research in general, the specific form of mobility examined here is conference travel. Conference travel and other short-term academic mobility (measured in days and weeks, and including domestic travel) have been under-researched in the academic mobility field, as often only longer, international stays of several months or years, or permanent moves are recognized as worthy of study (Henderson 2019b). However, there is a clear rationale for interlinking different forms of mobility and for recognizing the salience of short-term mobility in the wider field of academic mobilities. Firstly, there are clear links between short-term mobility such as conference travel and subsequent longer-term mobility and/or research collaboration (Kyvik and Larsen 1994; Smeby and Trondal 2005; Wang et al. 2017). Ignoring the role of short-term mobility in the biographies of academics means that its catalytic function is downplayed, and simultaneously participation in short-term mobility as an equality and diversity concern is negated. Secondly, by its nature, short-term mobility is likely to occur both more frequently than longer-term mobility, and to apply to more members of the academic profession. Shortterm mobility, which may include conferences, research trips, institutional visits, consultation meetings and training courses, makes up part of the fabric of academic work.

This article takes a sociological approach to researching academic mobility, which interrogates the underpinning values of mobility as well as the ways in which mobile subjects are constructed and the micro-processes of mobility (Henderson 2019b). In this article, theoretical tools from the sociology of work and the family are deployed, in particular the work of Arlie Hochschild (Hochschild 2012; Hochschild and Machung 2012). Using this theoretical foundation, the article articulates the construct 'sticky care'. The article argues that mobility brings out the stickiness of care, because ongoing care attachments that rely on presence are tested in a situation where a key carer is called upon to travel. Sticky care is conceptualized as an intertwined stickiness where care sticks to the mobile subject by sticky, stretchy strings, akin to the strings that are created when a 
shoe is pulled away from stepping in chewing gum. As such, sticky care is a concept that reveals deeply ingrained links between care and (im)mobility.

The empirical study that underpins the article was a project investigating the impact of caring responsibilities on academics' conference participation, 'In Two Places at Once' (Henderson 2019a; Henderson et al. 2018). The project included a research question which asked participants to discuss whether international conference travel involves different care strategies and processes to national conference travel. However, although there was a clear difference in some accounts between international and national conference travel, the participant interviews revealed the need to engage in a more general discussion of the extent to which academics with caring responsibilities felt able to travel at all. This paper explores participants' discussions of conference travel to unpack the notion that care causes immobility. The key questions that this paper speaks to are: what is it about care that can be said to explain immobility? How do academic-carers manage the tension between care and mobility? The overarching ambition of this article is at a conceptual level: to bring more complexity and nuance to the concept of care when it is mobilized as an explanatory factor for immobility and indeed for inequalities in the academic profession at large.

\section{Mobility, care and gender in academic careers}

Academic mobility is not a new phenomenon; academic scholarship has been characterized by the mobility of bodies and ideas since its inception (Kim 2009). However, arguably demonstrating evidence of mobility has become more formalized as a criterion of excellence or success in recent years (Herschberg et al. 2018), though this trend plays out in different ways in different regions and country contexts (Teichler 2017; Yang and Welch 2010; Ylijoki and Ursin 2013). Mobility framed in this way is particularly associated with research-oriented careers at elite institutions (Kenway and Fahey 2009), and is centred on intentional mobility for career progression purposes. There are also disciplinary differences in mobility expectations, with STEM subjects particularly focused on mobility credentials (Smeby and Trondal 2005). The formalization of mobility as a marker of success is inscribed in university rankings systems in the form of measures of internationalization (Marginson 2014). Mobility is also promoted in national and regional research education policy as key to the development of future research leaders and national research productivity (Henderson 2019b). Generally, the type of mobility that is promoted and valued is longer-term, international mobility. However, the mobility imperative is more widely experienced in an everyday sense in academic careers, in that ongoing practices of international and national collaboration and dissemination are expected and rewarded at an institutional level through promotion and progress review criteria (Sabharwal et al. 2020), and in that short-term mobility activities form the foundation for more substantial career mobility (Kyvik and Larsen 1994). Mobility, viewed longitudinally as an ongoing preoccupation of academics as they move through their working lives (Fahey and Kenway 2010), is firmly embedded in the normative ideal of a successful academic researcher.

Conference mobility is a major form of short-term academic mobility, and yet it has received little scholarly attention in the higher education field (Henderson 2015; Nicolson 2017). Conferences are perhaps so normalized in the academic career (Henderson 2020; Mair 2014) that they have seldom been singled out for their contribution to the construction of the mobile academic ideal, though conferences do appear as brief references in many publications on inequalities in the academic career. Indeed conferences seem to be integral to the image of a 
globetrotting academic, as conferences frequently appear as a trope in popular culture representations of academics (Henderson and Reynolds 2017). This trope also occurs in academic literature; for example Mobile Lives (Elliott and Urry 2010), a key text in mobilities studies, begins with an academic at a conference as the archetypal vignette of a mobile professional. Conference travel contributes to the construction of the mobile academic ideal for a reasonconferences are recognized as important extra-institutional spaces where landmark shifts occur in disciplines (see e.g. Bowles 2002; McCulloch 2012). Moreover, the importance of conference attendance for developing networks and collaborations has been demonstrated by a number of researchers (e.g. Campos et al. 2018; Mair and Frew 2018; Wang et al. 2017). Conference travel as a form of 'high mobility' that characterizes elite professionalism in the contemporary era (Viry and Kaufmann 2015) contributes to an academic's participation in a global elite of interconnected researchers. As such, this article argues for the recognition of conference travel as an important form of short-term mobility, in terms of frequency and contribution to career progression, but also in terms of its contribution to the construction of the mobile academic ideal.

The normative ideal of a mobile academic has been exposed by many researchers as problematic because, while presenting a neutral façade, its underpinnings are known to be gendered towards a masculine social role (Jöns 2011; Leemann 2010), classed towards an elite profile (Kastberg 2014) and reproductive of colonial geographies and geopolitical hierarchies (Obamba and Mwema 2009). In the burgeoning field of research on gendered inequalities in the academic profession, mobility is recognized as playing a role in reproducing gendered inequalities (e.g. Blackmore 2014; Nielsen 2017). The role of conferences in contributing to this phenomenon has yet to be fully explored. Thus far in conferences research relating to inequalities (which has predominantly constructed a gender binary between men and women ${ }^{1}$ ), studies have focused on the ways in which conferences are exclusionary at the time of the event, rather than mobility-related issues. Previous research has focused on gendered inequalities such as women opting for shorter presentation slots (Jones et al. 2014), sexual harassment (Jackson 2019; Flores, 2020), women being given less prestigious invited roles or organizing roles (Eden 2016; Walters 2018), women being asked fewer and asking fewer questions (Hinsley et al. 2017); intersectional conferences research has explored some of these issues in relation to gender and race or ethnicity (King et al. 2018; Timperley et al., 2020). There are also publications relating specifically to the issues of caring for children at conferences, which focus on the provision of facilities - or lack thereof - for childcare and breastfeeding at conferences (Bos et al. 2019; Lipton 2019). However, by focusing on the conference itself, existing research has somewhat neglected the wider context of academics' lives in facilitating or impeding conference mobility.

While the role of the mobility imperative - including conferences - in perpetuating gendered inequalities in academia seems to be clear, the connections between care and mobility need further unpacking. In relation to mobility, care is predominantly used as a gendered conceptual shorthand for describing the impediment to mobility caused by women's higher level of responsibilities in relation to caring responsibilities, particularly childcare responsibilities in the scenario of a heterosexual dyadic partnership between two cisgendered individuals (Beddoes and Pawley 2013). This then amounts to the use of care as an explanatory factor for (gendered) immobility, as exemplified in the following extracts (emphasis added):

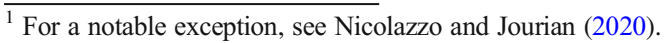


Domestic responsibilities and family obligations often restrict the work autonomy of younger female academics to greater extents than their male colleagues. (Nielsen 2017, pp. 149-150)

Young female academics with children face significant problems in aligning family responsibilities with academic work. (Dorenkamp and Süß 2017, p. 416)

While there is recognition in the literature that men are also involved in raising a family and are thereby also likely to be less mobile at the age of having children (Viry et al. 2015), there is also recognition that care is more of an impediment to mobility for women (ibid.). However, few studies of the academic profession go as far as to unpack what exactly care involves, and why care is an impediment to mobility for women academics in households where men are also present.

When denaturalized as concepts, catch-all terms such as 'childcare' and 'domestic responsibilities' can be seen to comprise complex and highly variable tasks which are also imbued with emotions and normative values. In an important study on this topic which makes inroads into the silence surrounding the practical workings of care in academics' lives, Beddoes and Pawley (2013) explored some of the factors which are concealed in these summative terms. For example, one participant recounted that she took more responsibility for housework, even though her partner was a stay-at-home parent; other women academics joked that they needed 'housewives' of their own to support them with their domestic responsibilities (p. 1578). This article argues that these scenarios need further exploration, and that ideas can be usefully drawn on from research on the sociology of work and the family to produce a more nuanced understanding of how care operates as a gendered impediment to mobility, i.e. what does a mobility-related scenario reveal about ongoing care practices (which are therefore potentially care practices of immobility). The next section develops an analytical approach to unpacking care in relation to academic mobility in general and in particular short-term, irregular mobility such as conference travel, through a novel conceptual construct: sticky care.

\section{Theorizing sticky care and mobility}

Sociological research on families and work recognizes that care needs to be unpacked both in terms of the complexity of tasks involved and the ideological and emotional facets that underpin these tasks (Hochschild 2012; Hochschild and Machung 2012). These two aspects underpin the construct sticky care which is elaborated in this section and then explored in later sections in relation to data from the 'In Two Places at Once' study. Sticky care is conceptualized as inherently linked with mobility, because the stickiness is revealed when mobility is planned or enacted. Arguably there is particular stickiness associated with irregular workrelated mobility such as conferences; researchers have found that professionals with regular business travel patterns do struggle to manage care and family life on the move, but have shown that these professionals (who are often men) are able to establish routines of care based on their mobility patterns (Ralph 2015; Willis et al. 2017). Conferences, and indeed most short-term academic mobility, fit into the category of irregular travel; this form of travel is more of an interruption to routines than a routine in and of itself, and as such sticky care takes shape in this article around these mobility-related interruptions.

The concept of sticky care in this paper is inspired by Sara Ahmed's (2014) discussion of the concept of stickiness in The Cultural Politics of Emotion, where Ahmed notes that a subject can remain sticky even when 'cut off from a sticky object' (p. 91) (in this case, care and 
home); when any academic travels, a sticky contact zone is revealed between the academic and their home life which can be explored in terms of both practical and emotional stickiness. In the context of this article, the stickiness can be imagined as akin to chewing gum, which remains on both surfaces (shoe and pavement) when pulled apart in the context of short-term mobility, with sticky stretchy strings trailing between.

\section{Sticky care-elaborate practices of care and household management}

The first aspect of sticky care is the complexity of the tasks which comprise care work, particularly if care is used with conceptual largesse to describe domestic responsibilities which also include housework. In The Second Shift, a famous study of dual-earner families, Arlie Hochschild and Anne Machung (Hochschild and Machung 2012, first published in 1989) researched families' everyday household practices. They explored families' 'gender strategies', i.e. 'plan[s] of action through which a person tries to solve problems at hand, given the cultural notions of gender at play' (ibid., p. 15). The 'plan of action' refers to larger family decisions such as one parent moving from full- to part-time work in order to care for children; it also refers to the micro-level of everyday family and household management. In the case of one couple, Greg and Carol, the couple proclaimed that they shared household duties. However Carol was responsible for 'daily and weekly chores such as cooking, shopping and laundry, in addition to such nondaily chores as shopping for children's clothes...' (ibid., p. 147). Greg's responsibilities consisted of 'nondaily chores: household repairs, paying bills, and repairing both cars' (p. 147). Carol took more responsibility for tasks which needed to be completed on a daily or weekly basis (which is a common gendered phenomenon; ibid.), while Greg's responsibilities could in principle be scheduled at his convenience. It is easy to see from this scenario how daily responsibilities are less compatible with mobility than nondaily tasks, but there is a further aspect to this matter.

The further aspect is the extent to which, in a partnership between two adults sharing the management of a household, a couple engage in 'specialized'/'split' or 'shared' models, where specializing/splitting refers to members of the partnership conducting different tasks, and sharing indicates that both members can perform tasks interchangeably (Kelly and Hauck 2015). While all couples engage in both of these strategies to an extent (ibid.), specializing is particularly strong in cisgendered heterosexual couples who follow (directly or in the legacy of; see Kanji and Samuel 2017) the breadwinner model, which is a gender strategy where typically the man supports the family economically and engages in nondaily tasks, while the woman works to maintain the home and family and engages in daily tasks. While dual-earning couples in principle challenge this model, there is a strong legacy of task specialization by gender (Hochschild and Machung 2012; Kitterød and Pettersen 2006). This then is the first aspect of sticky care: that the routine, ongoing care work (i.e. that which is less conducive to mobility) appears to stick particularly to women (here understood as cisgendered women in heterosexual dyadic partnerships, according to the norms discussed in the above sections), and indeed, from a mobility perspective, to stick women in place.

\section{Sticky care-ideological and emotional investments}

According to the above logic, the situation could be rectified at a practical level by (i) both members of a couple sharing daily and nondaily tasks more equally (i.e. both members taking responsibility for some daily tasks e.g. cooking and nondaily tasks e.g. home repairs) and (ii) 
couples practising more sharing rather than specialization in the distribution of tasks (i.e. both members sharing the same tasks interchangeably rather than both only having the specialized knowhow for a particular set of tasks). While this would seem to be the silver bullet to solving unequal access to mobility opportunities, what this solution neglects is the emotions and values that are attached to the attribution of tasks and specialism in the household.

These emotions and values are explored in The Second Shift (Hochschild and Machung 2012) as 'gender ideologies', which underpin gender strategies as 'beliefs about manhood and womanhood...that are forged in early childhood and usually anchored to deep emotion' (ibid., p. 15) and which are related to the ways in which power is enacted in spousal relationships. Strong expectations of femininity remain even in couples who are aligned with an egalitarian ideology, such that women are likely to experience more guilt about ceding care to others and to have stronger emotional investments in the standards kept in terms of care and the household (Hochschild and Machung 2012; Horsfield 1997). This then is the second aspect of sticky care - the ideological and emotional attachments relating to gendered legacies of care which mean that leaving the family and house in order to engage in short-term academic mobility is imbued with more emotional as well as practical obstacles for women.

Sticky care, then, is a double-faceted construct which includes both (i) elaborate practices of care and household management and (ii) the ideological and emotional investments which accompany and indeed influence these practices, both of which become sticky in a scenario where irregular mobility is called for, thus disrupting the ongoing care routine.

\section{The study: 'In Two Places at Once'}

This article draws on data from an in-depth, exploratory qualitative study entitled 'In Two Places at Once' (Henderson et al. 2018). The study used diary-interview method (Zimmerman and Wieder 1977), where 20 self-selected academics ${ }^{2}$ with caring responsibilities ${ }^{3}$ completed a $^{2}$ time log for one conference attended, on which they noted their preparation and catch-up tasks as well as interactions with caring responsibilities and/or co-carers while at the conference (Henderson 2019a). The time log provided the foundation for an in-depth interview in which participants discussed both the logged conference and their conference participation in general. The study took into consideration the principles of trustworthiness for solicited diary research outlined by Filep et al. (2017) (see Henderson et al. 2018, for greater detail on the study).

The participants were recruited on a first-come first-served basis through social media calls and calls on academic mailing lists. 19/20 participants were women, so inevitably the study produced findings that were particularly related to women academics. This is a recognized phenomenon in care-related studies with self-selected participants (Moreau and Robertson 2017). Given the focus on women and care in this paper, data from women participants only has been analysed. While the sample group was dominated by women participants, it should be noted that the study particularly sought variation in types of caring responsibilities, which was achieved. The most common caring responsibilities stated on the participant information

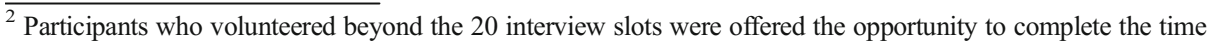
$\log$ without an interview. Nine participants engaged with the project in this way, but they are not included in this article due to the focus on the interview responses.

${ }^{3}$ Caring responsibilities were broadly defined as children, relatives, pets, friends, and kin, and the inclusive definition was emphasized in the call for participants, in order to move beyond the emphasis on children in the literature and relative silence around other caring responsibilities.
} 
sheet were children (16 participants), animals (six participants), partners (six participants), parents (four participants), but also included a sibling, a friend, and a children's club. Several participants listed a combination of two (five participants) or three (five participants) of the above categories.

The participants were predominantly located in the UK (14) but also included participants residing in Australia (three), USA (two) and Austria (one). Participants spanned all career stages. Conference destinations included UK (10), USA (three) and one each in Australia, Denmark, France, Germany, Japan, Kuwait and South Africa. Twelve participants attended a domestic conference and eight travelled abroad for a conference. Conferences varied from one to five days, with three days being the mode (eight participants). Eleven participants travelled for longer than the period of the conferences; eight participants travelled for the same number of days as the conference; one participant travelled for a shorter duration than the conference. For most participants, travel did not exceed a week; however, four participants travelled for longer than a week (up to two months) and included other activities such as seminars or fieldwork in the same trip. Only one participant was accompanied by someone for whom they were a carer (a child) to the conference. As a final note, due to anonymity concerns when researching academics, who can easily be identified as semi-public figures, little identifying information is provided about the participants in this paper.

Following verbatim transcription of the interviews, all interviews were initially read alongside the time logs in order to cross-reference between the two sources of data. For the purposes of this article, firstly participants' answers from the interview discussion regarding the feasibility of international and national conference travel were extracted, collated into one document and thematically analysed for issues raised regarding conference travel (e.g. time away, distance). The thematic analysis revealed the need for a more theoretically informed, discursive approach to analysis (Davies 2006) due to the intricacies of participants' discussions of these issues. The data extracts were re-analysed to explore the construction of care strategies as well as statements which reflected ideological/emotional discourses of care in relation to mobility, as per the sticky care construct elaborated in the previous section. The extracts were then re-read against participants' interviews and time logs to contextualize participants' statements in their wider accounts.

\section{Unpacking care as an explanatory factor for gendered academic immobility}

As an irregular form of work-related travel which is short and intense, conference travel constitutes a particular type of mobility which is revelatory of the ways in which care is organized within academics' everyday lives. Unlike regular commuting, where mobile care routines are created and maintained (Willis et al. 2017), conference travel interrupts care routines. The effect of the interruption, and the ways in which it is understood and managed by mobile academic subjects, brings to light the extent to which academic-carers are constituted as im/mobile subjects within their care set-ups. Care is revealed as sticky in relation to the ease/ difficulty with which mobile academic subjects are able to detach themselves - practically and emotionally - from the care set-up in order to engage in irregular travel. As per the overarching questions for this paper, this section addresses what it is about care that can be said to explain immobility, and how academic-carers manage the tension between care and mobility, using the construct of sticky care elaborated earlier in the article to structure this analysis. 
The first aspect of the sticky care construct, then, involves identifying practices of care and household management which appear sticky when conference travel is planned and enacted. Applying this first aspect to the participants' accounts involved identifying strategies in the interview data for managing care and mobility, along the lines of the 'gender strategy' concept outlined in Hochschild and Machung's (2012) work. An overarching strategy which was common across all participants' accounts, no matter the care type/s, was to reduce the impact of conference travel on caring responsibilities. Most of the participants were responsible for daily tasks (e.g. cooking) within their households, and discussed living in couples with specialized task distribution strategies (where members of the partnership engage in different tasks). This domestic arrangement, which is disguised by the outward appearance of a dualearning couple, results in there being a higher impact of travel for the daily-task specialist (e.g. the person that does all the cooking) than for the nondaily-task specialist (e.g. the person that does all the home repairs) - an imbalance which we know from the literature outlined above to be highly gendered towards women. For many participants, this resulted in a strategy of reducing the frequency of travel. Regarding instances where they did travel, participants revealed mobility strategies which sought to reduce the impact of being away on caring responsibilities and the household. This section outlines two dominant strategies identified by participants: (i) reducing night/s spent away, and (ii) reducing the time to get back.

As discussed in the sticky care section, it is not enough to examine care strategies as if they could be easily rectified, for they are rooted in legacies of gendered household management which place ultimate responsibility for care and the household onto women (in a heterosexual partnership), thus requiring physical presence. Sticky care does not just involve being stuck in place by daily-task specialism - the second aspect of sticky care relates to emotions and values attached to gendered caring roles. Thus, the analysis also looks between the lines of the data on participants' practical strategies, in order to further unpack the complexity that underpins care as an explanatory factor for gendered immobility.

\section{Strategy 1: reduce night/s away}

A major strategy that participants employed to manage the tension between care and conference travel was to actively work to reduce the length of time they were away from home. The extent of these time restrictions varied between participants. Some participants discussed the impossibility of, or challenges involved in, staying away overnight. P2, who was based in the central area of England, stated that having to stay away in London (i.e. South East of England) involved equivalent obstacles to staying abroad; P1, based in the South of England, echoed this by stating that attending a conference in the North of England would involve the same challenges as going to Japan. P12 simply stated that staying anywhere overnight was impossible' for her given her caring responsibilities (two children aged five and two). Other participants had adopted specific policies regarding the maximum number of nights they would stay away, including two nights (P18) and four nights (P17). As noted in the Study section, many participants were away for exactly the same number of days as the duration of the conference. This appeared in participants' accounts as a deliberate strategy to reduce the amount of time away; both P18 and P17 shaved off parts of the conference to incorporate travel time without adding extra nights away. P17 stated she would consider a conference in Chicago, USA, but would have to incorporate the two 8-h flights within the four nights - she ruled out a conference 
in Australia due to the 28-h flight, which could not be accommodated within the four nights policy. P16 flew to the USA from Austria overnight and went directly to the conference from the airport in order to avoid staying away for an extra night.

The impact of these strategies on the conference experience was clear from participants' accounts. Firstly, participants missed parts of conferences, with the result that they arrived at the conference feeling that they had already missed out or missed papers or social events. Secondly, participants did not allow their bodies time to recover from travel—or to adjust to being away, meaning that they were often jetlagged, fatigued and disorientated at the conferences they had worked so hard to attend. Importantly, these academics seem to have succeeded at conference mobility in that they had attended conferences, some of them travelling long distances over international borders to do so, but concealed within this is a limited experience of the conference due to the strategy of limiting time away.

So why did participants place these limits on their conference mobility? For daily-task specialists, the diaries and post-conference interviews showed that an extra night away presents numerous logistical challenges for care practices, such as preparing food in advance and doing online grocery orders either in advance or from the conference, ensuring children's clothes were set out in advance, packing children's activity bags such as sports kits and music lesson materials for the duration of the conference, creating detailed lists or spreadsheets to show what needed to happen during the participant's days away and hiring a cleaner for extra days. In the sticky care construct, responsibility for these ongoing tasks is represented as sticky strings between the mobile academic-carer and the home. The participants' accounts showed that the concept of care in relation to academic mobility needs to take into account that, in households operating with a specialist model, the daily-task specialist is automatically constituted as less mobile, and will experience a stickier form of sticky care when the routine is interrupted by irregular travel. Simply put, one major facet of care as an explanatory factor for academic immobility is not care writ large, but rather care in the form of daily-task specialism.

As noted earlier in the article, rebalancing daily and nondaily tasks and moving from a specialist to a shared model would be a practical solution to some subjects being more mobile than others, but this would miss the underlying social reasons which underpin the distribution of care and household responsibilities. For, while participants set out clear and rational explanations for why overnight travel was challenging at a practical level, there was a further layer of explanation which resonates with the second aspect of the sticky care construct - the ideological and emotional investments which accompany and influence care/mobility practices. In addition to the practicalities discussed above, participants expressed their resistance to overnight travel (for one night or multiple nights) in terms of the symbolic significance of absence from their caring responsibilities - children in particular. Here, the sticky strings of daily-task specialism are imbued with further stickiness, of a symbolic kind.

The intersection between logistical and symbolic challenges is captured perfectly in P15's account:

It [four days] feels like it's a long time to be away. I mean both in terms of my caring responsibilities and arrangements, but also just, you know, four days away from my family is quite a lot. (Emphasis added)

Here, P15 is discursively negotiating both the practical and ideological meanings of travel through an emotional lens ('feels like'). She indicates that 4 days away involves 
significant labour on her part to ensure that arrangements are in place, but extends this with the notion that 4 days away 'is quite a lot'. This seems to represent the symbolic gesture that is involved in a carer (particularly a mother) voluntarily travelling away from caring responsibilities-here the mobile academic ideal directly collides with the ideal carer role (see also Henderson and Moreau 2020). Echoing P15's discursive construction, P11 stated that staying away for a conference 'feels like a much bigger deal'. P5 referred to planned international travel as a 'big statement', a

big kind of emotional physical thing to be like, 'I'm putting myself in a position that I'm going to be twelve hours away from my family'. (Emphasis added)

This excerpt again highlights the disjuncture between academic and care ideals, where the participant frames her planned travel in an internal dialogue where she literally sets out the 'big statement' she is making by 'putting [her]self' into the mobile academic ideal — which has the direct implication of physically removing herself from her family. The internal dialogue, which is a recognized feature of women's challenges to reconcile professional with care roles (Hochschild and Machung 2012), recurred in participants' accounts as they explored the challenges associated with enacting professional and care-related activities which were practically and ideologically incompatible (Amsler and Motta 2019). Arguably, conference travel is particularly challenging in this respect as it is perceived as both optional or luxurious and vital (Henderson 2020), so it is even more difficult to justify potentially disrupting care routines for travel purposes. The night/s away strategy thus reveals that care as an explanatory factor for gendered immobility both comprises stickiness in terms of daily-task specialism at a practical level, and in terms of a gendered ideal of physical presence at home, which is maintained at an ideological and emotional level.

\section{Strategy 2: reduce time to get back}

A combination of daily-task specialism and an ideal of physical presence are further borne out in the second dominant strategy that participants used to manage the tension between care and mobility: namely, reducing the time to get back. Several participants discussed the notion of the time it would take to get back home if unforeseen events occurred, and actively chose conferences with this in mind. This strategy involved limiting the distance travelled (measured in the time to travel home as well as frequency of transport options) in case they had to spontaneously return home. Some participants discussed this strategy in relation to examples of places they would rule out: P17 ruled out travelling to Australia from the UK; P15 noted that she was going to attend a conference in Sweden and had chosen this above a conference happening at the same time in California, USA, because it would be 'easier to get home' to the UK from Sweden; P16 stated that, if she had to choose between conferences of the same academic value in London and Mexico, she would choose London, based on London being less 'far away' from her country of residence. This strategy limited academics' mobility by drawing an invisible line on the map as to where they could travel that would enable them to 'get back', thus restricting the potential zone of networking that they could engage in.

As with the 'night/s away' strategy, the get back strategy is underpinned with symbolic significance relating to a carer engaging in planned, intentional travel. P15 found herself weighing up whether to attend a conference in Sweden or California (from the UK), where she 
would be away for the same number of nights for either conference, but California 'seemed like an awfully long way':

Actually, it's much easier - and this was sort of going through my head - that it's much easier for me to get home from Sweden than it is to get home from California. And $I$ don't even know what circumstances I was imagining [where] I would have to get home. (Emphasis added)

Again the internal dialogue between the two incompatible ideals is represented here ('going through my head') - crucially, P15 alludes to the symbolic nature of the get back strategy by stating that she is unsure of what she would need to get back for. Participants appeared to be symbolically attached to their homes and caring responsibilities by figurative sticky, stretchy strings which, in addition to limiting the zone of mobility, also seemed to pull them homeward when they were engaged in conference travel. P5, for example, discussed the temptation to leave a conference early if it were close to home; she described a scenario where, if the conference is nearby, she 'get[s] a bit more distracted' and, if the conference is not of the standard or relevance she had expected, she begins to think about how she could 'just get in the car and go home'. The care schedule begins to play out in her mind and she aligns the conference day with the care schedule, thinking "If I leave now, I can be home in time to do the nursery pick up"". The homeward pull can be couched in practical terms - as noted above, daily-task specialists tend to have put many more arrangements in place to cover for their absence than nondaily-task specialists. Because conference mobility is irregular travel, in general, these are one-off or infrequent arrangements which could easily go wrong, so there is higher risk in the daily-task specialist travelling. Knowledge of this risk contributes to constituting the dailytask specialist as stuck in place. The diaries and interviews contained many examples of risk management and plan failure due to daily-task specialism, such as the pets not being fed, children being dressed in the wrong clothes or having the wrong sheets on their bed, washing and cleaning not being done and school pick-up arrangements not working. As discussed above, underpinning the practical terms is the ideological aspect where women, particularly mothers, often take ultimate responsibility for the daily management of care and the household.

As noted above, some participants were not willing or able to stretch the cords enough to test them - tight limitations on night/s away also created easy get back conditions. However, participants who had engaged in recent long-distance international conference travel revealed an interesting phenomenon. This took the form of a distance frontier where participants had stretched the cords so far that they could not get back even if they needed to. P1, who had travelled to Japan from the UK, expressed this as follows: 'I was so far away I had to distance myself' (emphasis added). She differentiated between attending a conference 'in the immediate vicinity' (i.e. at her university), where she could 'nip home', and being fully 'away', where she 'can't just be back instantly'. Similarly, P17 noted that, while at conferences in her country of residence she feels she is the 'emergency contact', this recedes with international conference travel because 'it's actually physically being out of the country and therefore not able to do anything about it'. The distance frontier provides an interesting angle from which to explore the get back strategy from an ideological/emotional perspective. Traversing the frontier (which was itself a subjective boundary) seemed to intervene in - and therefore expose - the ultimate care/household responsibility which participants otherwise maintained, in spite of careful preparations and the presence of other trusted co-carers and multiple back-up plans.

It is important to highlight that academics with caring responsibilities do value conference travel, as gendered expectations of motherhood (in particular) include assumptions of 
acquiescence to gendered immobility (Nielsen 2017; Viry et al. 2015). For the participants in the study, conference mobility was valued for a number of reasons and was discussed in its catalytic function as leading to further collaborations as well as having intrinsic value as a vehicle for sharing research, maintaining an academic identity and research profile, and also providing occasions for work-related socializing (Mair and Frew 2018). Equally strong was the thread regarding the challenges posed to conference mobility by ongoing caring responsibilities. Many participants had started their careers without children and other caring responsibilities and were therefore able to compare their mobility before and after the increased level of care. P18, referred to above in relation to her comparative research, had found that her reduction in mobility was 'putting a stall on her career'. Indeed P17 discussed having reshaped her whole research network since having a child to target colleagues located in places that could be reached with only one night away, and P5 (who was based in the UK with a research specialism in international development) said she had cancelled attending a conference in China and would reject research propositions to work in India because of the difficulties of managing post-travels care with the added factor of jetlag. Across participants, there was a clear pattern regarding the impact of care on conference mobility: fewer conferences, trips of a shorter duration, destinations which are closer to home. While it is easy to attribute these mobility restrictions to care as an explanatory factor, it is important to note that this care is not just any care - it is care in the form of daily-task specialism and a gendered ideal of physical presence.

\section{Conclusion}

Unpacking care as an explanatory factor for academic immobility is a key conceptual gesture in moving towards a more comprehensive, nuanced understanding of gendered inequalities in the academic profession. This article has focused on conference mobility both as a form of short-term mobility (and a catalyst for further mobility) and also as a practice that contributes to the construction of a mobile academic ideal. While the importance of conferences for academic careers is at times downplayed (Henderson 2020), it is clear from this study that the effects of missing out on conference attendance are felt keenly by those who are less able to engage in high mobility (Viry and Kaufmann 2015). It is equally clear that academics with caring responsibilities - predominantly women academics in this study - struggle to attend conferences and that their conference attendance is limited to fewer conferences, trips of a shorter duration and destinations which are closer to home. Applying the construct of sticky care to participants' accounts revealed two dominant strategies: 'reduce night/s away' and 'reduce time to get back'. Both strategies were related to the fact that conference mobility, as an irregular form of mobility, was experienced as an interruption to ongoing care routines, which constitute carers as subjects with limited mobility. Interrupting these routines was more challenging for daily-task specialists, who had to put more arrangements in place to replace their care and household functions. However, there were also emotional and ideological aspects underpinning what otherwise appeared to be practical obstacles to mobility. The mobility strategies of reducing night/s away and reducing travel time in order to be able to get back are thus also gendered care strategies. It is impossible to fully disentangle imbalances in care/household task distribution from the ideal of physical presence that limits carers (particularly women) engaging in planned, intentional travel.

Care as an explanatory factor for gendered academic immobility is a complex terrain. Even while exploring care through the two mobility strategies outlined here, further strategies were revealed for which this article does not have scope to explore. These included engaging in preparatory tasks 
where participants attempted to pre-empt the tasks that would be required during their absence and engaging in substantial virtual management of the care/household tasks from the conference. In addition, it is also necessary to note that each participant's strategies differed according to the nature of their caring responsibilities, and also according to their life circumstances (Henderson et al. 2018); these variations also merit further exploration. Notable areas for further exploration which appeared in the study included men academics, sole parents, same-gender couples and/or couples with trans and/or non-binary members and/or academics living outside of the couple structure, dual career academic couples, migrant academics, academics with complex and multiple caring responsibilities, academics practising a faith and academics living in remote locations away from travel hubs. All of these areas have implications for the intersection between care and mobility and reveal the scope for further research in this area.

The risk of not engaging in wider sociological analyses of care in relation to academic mobility and to the academic profession more generally is that schemes to redress inequality may reproduce rather than redress the problem, by associating women with 'the care problem'. For care is not a barrier in its own right, but rather caring and household responsibilities are enmeshed in gendered social practices and ideologies which position women as more indispensable in the home than men. However, this does not mean that we should accept this imbalance as 'too entrenched in a larger gender system to be changeable' (Beddoes and Pawley 2013, p. 1582), and it is important to emphasize that this article does not argue for the disbanding of schemes such as carer travel bursaries and conference childcare profession, which do alleviate some of the mobility challenges. The article argues that, even while putting in place small-scale solutions, the long view should be maintained, or we risk reproducing the deterministic essentialism that women are less mobile than men because of care.

Acknowledgements The project was generously funded by the University of Warwick Research Development Fund and Institute for Advanced Studies. Thanks to Julie Mansuy and Xuemeng Cao for their assistance with the project. Thanks also to James Burford, Holly Henderson, Barbara Read, Charikleia Tzanakou and the anonymous reviewers for their helpful comments on earlier versions.

\section{Compliance with ethical standards}

Conflict of interest The author declares that she has no conflict of interest.

Open Access This article is licensed under a Creative Commons Attribution 4.0 International License, which permits use, sharing, adaptation, distribution and reproduction in any medium or format, as long as you give appropriate credit to the original author(s) and the source, provide a link to the Creative Commons licence, and indicate if changes were made. The images or other third party material in this article are included in the article's Creative Commons licence, unless indicated otherwise in a credit line to the material. If material is not included in the article's Creative Commons licence and your intended use is not permitted by statutory regulation or exceeds the permitted use, you will need to obtain permission directly from the copyright holder. To view a copy of this licence, visit http://creativecommons.org/licenses/by/4.0/.

\section{References}

Ahmed, S. (2014). The cultural politics of emotion (Second ed.). Edinburgh: Edinburgh University Press.

Amsler, S., \& Motta, S. C. (2019). The marketised university and the politics of motherhood. Gender and Education, 31(1), 82-99.

Beddoes, K., \& Pawley, A. L. (2013). Different people have different priorities: Work, family balance, gender, and the discourse of choice. Studies in Higher Education, 39(9), 1573-1585. 
Blackmore, J. (2014). 'Wasting talent'? Gender and the problematics of academic disenchantment and disengagement with leadership. Higher Education Research \& Development, 33(1), 86-99.

Bos, A. L., Sweet-Cushman, J., \& Schneider, M. C. (2019). Family-friendly academic conferences: A missing link to fix the "leaky pipeline"? Politics, Groups, and Identities, 7(3), 748-758.

Bowles, G. (2002). Putting our heads together: Some personal recollections of NWSA National Conventions, 1979-1983. NWSA Journal, 14(1), 124-133.

Campos, R., Leon, F., \& McQuillin, B. (2018). Lost in the storm: The academic collaborations that went missing in hurricane ISSAC. The Economic Journal, 128(610), 995-1018.

Davies, B. (2006). Constituting the feminist subject in poststructuralist discourse. Feminism \& Psychology, 16(1), $87-103$.

Dorenkamp, I., \& Süß, S. (2017). Work-life conflict among young academics: Antecedents and gender effects. European Journal of Higher Education, 7(4), 402-423.

Eden, D. (2016). Women's participation in academic conferences in Israel. Journal of Higher Education Policy and Management, 38(4), 406-421.

Elliott, A., \& Urry, J. (2010). Mobile lives. In London. New York, NY: Routledge.

Fahey, J., \& Kenway, J. (2010). International academic mobility: Problematic and possible paradigms. Discourse: Studies in the Cultural Politics of Education, 31(5), 563-575.

Filep, C. V., Turner, S., Eidse, N., Thompson-Fawcett, M., \& Fitzsimons, S. (2017). Advancing rigour in solicited diary research. Qualitative Research. 1468794117728411.

Henderson, E. F. (2015). Academic conferences: Representative and resistant sites for higher education research. Higher Education Research \& Development, 34(5), 914-925.

Henderson, E. F. (2019a). Academics in two places at once: (Not) managing caring responsibilities at conferences. In R. Finkel, B. Sharp, \& M. Sweeney (Eds.), Accessibility, inclusion, and diversity in critical event studies (pp. 218-229). London; New York: Routledge.

Henderson, E. F. (2019b). A PhD in motion: Advancing a critical academic mobilities approach (CAMA) to researching short-term mobility schemes for doctoral students. Teaching in Higher Education, 24(5), 678-693.

Henderson, E. F. (2020). Gender, definitional politics and 'live' knowledge production: Contesting concepts at conferences. London; New York: Routledge.

Henderson, E. F., \& Moreau, M.-P. (2020). Carefree conferences? Academics with caring responsibilities performing mobile academic subjectivities. Gender and Education, 32(1), 70-85.

Henderson, E. F., \& Reynolds, P. J. (2017). "Novel” delegates: Representations of academic identities in fictional conferences. Paper presented at the Society for Research into Higher Education Annual Conference, Newport, Wales.

Henderson, E. F., Cao, X., \& Mansuy, J. (2018). In two places at once: the impact of caring responsibilities on academics' conference participation: final project report. Coventry: Centre for Education Studies, University of Warwick. https://doi.org/10.31273/CES.06.2018.001.

Herschberg, C., Benschop, Y., \& van den Brink, M. (2018). Selecting early-career researchers: The influence of discourses of internationalisation and excellence on formal and applied selection criteria in academia. Higher Education, 76(5), 807-825.

Hinsley, A., Sutherland, W. J., \& Johnston, A. (2017). Men ask more questions than women at a scientific conference. PLoS One, 12(10), e0185534.

Hochschild, A. R. (2012). The managed heart: Commercialization of human feeling (updated with a new preface). Berkeley; London: University of California Press.

Hochschild, A. R., \& Machung, A. (2012). The second shift: Working families and the revolution at home (revised and with a new afterword). New York; London: Penguin Books.

Hook, G. A. (2016). Sole parent students and higher education: Gender, policy and widening participation. Basingstoke: Palgrave Macmillan.

Horsfield, M. (1997). Biting the dust: The joys of housework. London: Fourth Estate.

Jackson, L. (2019). The smiling philosopher: Emotional labor, gender, and harassment in conference spaces. Educational Philosophy and Theory, 51(7), 693-701.

Jones, T. M., Fanson, K. V., Lanfear, R., Symonds, M. R. E., \& Higgie, M. (2014). Gender differences in conference presentations: A consequence of self-selection? PeerJ, 1-15.

Jöns, H. (2011). Transnational academic mobility and gender. Globalisation, Societies and Education, 9(2), 183-209.

Kanji, S., \& Samuel, R. (2017). Male breadwinning revisited: How specialisation, gender role attitudes and work characteristics affect overwork and underwork in Europe. Sociology, 51(2), 339-356.

Kastberg, S. M. (2014). "Sensitive fences": The im/mobility of working class academics. In N. Maadad \& M. Tight (Eds.), Academic mobility (pp. 219-242). Bingley: Emerald.

Kelly, M., \& Hauck, E. (2015). Doing housework, redoing gender: Queer couples negotiate the household division of labor. Journal of GLBT Family Studies, 11(5), 438-464.

Kenway, J., \& Fahey, J. (2009). Academic mobility and hospitality: The good host and the good guest. European Educational Research Journal, 8(4), 555-559. 
Kim, T. (2009). Shifting patterns of transnational academic mobility: A comparative and historical approach. Comparative Education, 45(3), 387-403.

King, L., Mackenzie, L., Tadaki, M., Cannon, S., McFarlane, K., Reid, D., \& Koppes, M. (2018). Diversity in geoscience: Participation, behaviour, and the division of scientific labour at a Canadian geoscience conference. Facets, 3, 415-440.

Kitterød, R. H., \& Pettersen, S. V. (2006). Making up for mothers' employed working hours?: Housework and childcare among Norwegian fathers. Work, Employment and Society, 20(3), 473-492.

Kyvik, S., \& Larsen, I. M. (1994). International contact and research performance. Scientometrics, 29(1), 161172.

Leemann, R. J. (2010). Gender inequalities in transnational academic mobility and the ideal type of academic entrepreneur. Discourse: Studies in the Cultural Politics of Education, 31(5), 605-625.

Lim, M. A., \& Williams Øerberg, J. (2017). Active instruments: On the use of university rankings in developing national systems of higher education. Policy Reviews in Higher Education, 1(1), 91-108.

Lipton, B. (2019). Conference baby: Gendered bodies, knowledge, and re/turning to academia. Qualitative Inquiry, 25(2), 160-162.

Mair, J. (2014). Conferences and conventions: A research perspective. London; New York: Routledge.

Mair, J., \& Frew, E. (2018). Academic conferences: A female duo-ethnography. Current Issues in Tourism, 21(18), 2152-2172.

Marginson, S. (2014). University rankings and social science. European Journal of Education, 49(1), 45-59.

McCulloch, G. (2012). The standing conference on studies in education, sixty years on. British Journal of Educational Studies, 60(4), 301-316.

Moreau, M.-P., \& Robertson, M. (2017). Careers and carers: Career development and access to leadership positions among academic staff with caring responsibilities. London: Leadership Foundation for Higher Education.

Nicolazzo, Z., \& Jourian, T. J. (2020). 'I'm looking for people who want to do disruption work': Trans* academics and power discourses in academic spaces. Gender and Education, 32(1), 56-69.

Nicolson, D. J. (2017). Academic conferences as neoliberal commodities. Basingstoke: Palgrave Macmillan.

Nielsen, M. W. (2017). Reasons for leaving the academy: A case study on the 'opt out' phenomenon among younger female researchers. Gender, Work and Organization, 24(2), 134-155.

Obamba, M. O., \& Mwema, J. K. (2009). Symmetry and asymmetry: New contours, paradigms, and politics in African academic partnerships. Higher Education Policy, 22(3), 349-371.

Ralph, D. (2015). Work, family and commuting in Europe: The lives of Euro-commuters. Basingstoke: Palgrave MacMillan.

Sabharwal, N. S., Henderson, E. F., \& Joseph, R. S. (2020). Hidden social exclusion in Indian academia: Gender, caste and conference participation. Gender and Education, 32(1), 27-42.

Smeby, J.-C., \& Trondal, J. (2005). Globalisation or Europeanisation? International contact among university staff. Higher Education, 49(4), 449-466.

Teichler, U. (2017). Internationally mobile academics: Concept and findings in Europe. European Journal of Higher Education, 7(1), 15-28.

Timperley, C., Sutherland, K. A., Wilson, M. \& Hall, M. (2020). He moana pukepuke: Navigating gender and ethnic inequality in early career academics' conference attendance. Gender and Education, 32(1), 11-26.

Viry, G., \& Kaufmann, V. (Eds.). (2015). High mobility in Europe: Work and personal life. Basingstoke Hampshire: Palgrave Macmillan.

Viry, G., Vincent-Geslin, S., \& Kaufmann, V. (2015). Family development and high mobility: Gender inequality. In G. Viry \& V. Kaufmann (Eds.), High mobility in Europe: Work and personal life (pp. 153-179). Basingstoke Hampshire: Palgrave Macmillan.

Walters, T. (2018). Gender equality in academic tourism, hospitality, leisure and events conferences. Journal of Policy Research in Tourism, Leisure and Events, 10(1), 17-32.

Wang, W., Bai, X., Xia, F., Bekele, T. M., Su, X., \& Tolba, A. (2017). From triadic closure to conference closure: The role of academic conferences in promoting scientific collaborations. Scientometrics, 113(1), 177-193.

Willis, C., Ladkin, A., Jain, J., \& Clayton, W. (2017). Present whilst absent: Home and the business tourist gaze. Annals of Tourism Research, 63(Supplement C), 48-59.

Yang, R., \& Welch, A. R. (2010). Globalisation, transnational academic mobility and the Chinese knowledge diaspora: An Australian case study. Discourse: Studies in the Cultural Politics of Education, 31(5), 593-607.

Ylijoki, O.-H., \& Ursin, J. (2013). The construction of academic identity in the changes of Finnish higher education. Studies in Higher Education, 38(8), 1135-1149.

Zimmerman, D. H., \& Wieder, D. L. (1977). The diary: Diary-interview method. Urban Life, 5(4), 479-498.

Publisher's note Springer Nature remains neutral with regard to jurisdictional claims in published maps and institutional affiliations. 